\title{
Learning Analytics - A Growing Field and Community Engagement
}

\author{
Dragan Gašević, Shane Dawson, Negin Mirriahi, and Phillip D. Long \\ Editors, Journal of Learning Analytics \\ jla.editorial@gmail.com
}

\begin{abstract}
This editorial discusses events that marked the period since the publication of the previous issue - the $5^{\text {th }}$ International Conference on Learning Analytics and Knowledge (LAK 2015), Learning Analytics Summer Institutes (LASIs 2015), and Learning Analytics Policy Briefing in the European Parliament. This period saw releases of two important publications for systemwide implementation of learning analytics in higher education published by Jisc and the Australian Government's Office for Learning and Teaching. An important recognition of the maturation of the field of learning analytics is the recent publication of the 2015 Google Scholar Metrics identifying the LAK proceedings as the only conference proceedings among the 20 most cited publication venues in educational technology. Building bridges for enhancing impact is another important activity for the field maturation through developing linkages of learning analytics with educational data mining, user modeling, the learning sciences, technology enhanced learning, cyber-learning, and learning at scale. This editorial also introduces a special section published in this issue dedicated to the exploration of connections between selfregulated learning and learning analytics, introduces two regular research papers featured in this issue and describes several special sections that will be published in future issues of the journal.
\end{abstract}

Keywords: learning analytics, self-regulated learning, Society for Learning Analytics Research, bridge building, Google Scholar

\section{WHAT HAS HAPPENED IN THE MEANTIME?}

Welcome to the first issue of the second volume of the Journal of Learning Analytics. The issue comes on an exciting wave of continuous growth for the field. Numerous events and publications have marked the steady maturation of the field among a wide international community of learning analytics researchers and practitioners. For example, the centrepiece annual event, organized by the Society for Learning Analytics Research (SoLAR), is the International Conference on Learning Analytics \& Knowledge (LAK 2015). This year LAK15 reached its highest number (320) of participants leading to a fully-capped conference. The event was impeccably organized by Marist College with the outstanding leadership of Josh Baron and his co-leads Grace Lynch (SoLAR) and Nicole Maziarz (Marist College). The conference also featured an exciting program arranged by the conference program co-chairs (Paulo Blikstein, Agathe Merceron, and George Siemens), practitioner track chair (Alan Berg), doctoral consortium chairs (Simon Buckingham Shum, Katherine Maillet, Dan Suthers, and Stephanie Teasley), workshop and tutorial chairs (Christopher Brooks and Negin Mirriahi), and demonstrations and posters chairs (Gregory 
Dyke and Marcelo Worsley). The community owes many thanks to Marist College and a small army of individuals and sponsoring organizations/partners who invested much time, hard work and donations to further promote the field. While academic recognition is often attributed to research publications and awards, the role of those who serve the community through the organization of field development and growth events needs to receive at least as equal recognition. As per our tradition established with the LAK 2013 and LAK 2014 editions, a special section of the journal showcasing some of the LAK 2015 papers is in preparation and scheduled for publication in issue three of this volume.

The hard work and commitment to high quality research and practice in learning analytics has already payed off. We were very excited to learn that that the ACM proceedings from the LAK conference are the only proceedings in the top 20 most cited publication venues in the field of educational technology according to the 2015 Google Scholar Metrics ${ }^{1}$. Everyone who has supported the conference through their organization, paper authoring, reviews, sponsorship, workshops and promotions deserve our many thanks. The rapid rise and quality of the LAK proceedings reflects very positively on the efforts of the entire community - congratulations. We are confident that this achievement is merely the start of a long and fruitful future for learning analytics and is a good motivator for all us to stay committed to the core values of the field - high quality, inclusiveness, openness, transparency, and multidisciplinarity.

The recognition of contributions, open and inclusive have been core values that SoLAR has tried to promote and follow. We have previously discussed there is a need for ongoing reflections and evaluations of the emerging research networks forming in the learning analytics literature (Dawson, Gašević, Siemens, \& Joksimovic, 2014; Mirriahi, Gasevic, Dawson, \& Long, 2014). These reflections help to identify clusters of emerging research and also raise awareness of individuals developing their careers and interest in the field. The need for community growth and leadership turnover is critical if we are to maintain a strong and fertile presence. To date many individuals have contributed to the development of SoLAR and the field. A bulk of that has been completed through activating ties of informal networks established around our emerging field. Presently, SoLAR has consolidated its structure and governing procedures and there a many ways individuals can be involved in supporting and leading the direction of the field via the governing body of SoLAR. For the first time, SoLAR held elections that are open to all its members for the first four seats available on the Executive Committee (EC). We welcome Abelardo Pardo, Hendrik Drachsler, Srecko Joksimovic (student representative), and Leah Macfadyen to the SoLAR EC. The term on the EC ended for George Siemens (the founding President of SoLAR), Erik Duval and Nancy Law. George, Erik and Nancy have made great contributions to the field in these early critical years and deserve many thanks and much appreciation for their hard work and commitment. As part of this process, Dragan Gasevic was elected as President for a two year term (2015-2017). Other office bearers are Simon Buckingham Shum (Vice-President), Philip Long (Vice-President), Caroline Haythornhwaite (Secretary), and Shane Dawson (Treasurer). We strongly encourage all members of the community to be involved and run for seats on the SoLAR EC or general committee for the 2016 elections.

\footnotetext{
${ }^{1}$ https://scholar.google.ca/citations?view_op=top_venues\&hl=en\&vq=soc_educationaltechnology
} 
The Learning Analytics Summer Institutes (LASIs) have been well established as "an awareness-raising, capacity-building, international network of events, where researchers and practitioners meet to share work, ideas and opportunities for future collaborations (Buckingham Shum \& Ochoa, 2015). The major news for LASIs 2015 is that they are now organized as a network of distributed events happening across the world. This is unlike LASIs 2013 and LASIs 2014 , which were designed and organised as a central hub (at Stanford University in 2013 and at Harvard University in 2014), with several localised yet connected events. This development recognises the broader learning analytics community and supports those members who are interested in organizing more local events that serve the needs of their geographic regions. The LASI events that were or are planned to be held during 2015 include: Aalborg (Denmark), Bilbao (Spain), Boston (USA), Washington DC (USA), Wellington (New Zealand), Pretoria (South Africa), Wuhan (China), and Sydney (Australia). The coordinators of the LASI network Simon Buckingham Shum and Xavier Ochoa together with the numerous organizers of the regional LASI events deserve many thanks for their hard work and contributions.

Several other events and publications of high impact for policy and strategy of learning analytics marked the period between the publication of this and the past issue of the journal. The EU-funded LACE project organized a learning analytics policy briefing in the European Parliament in Brussels, Belgium (LACE Project, 2015). This event was of strategic importance for the field building as it increased awareness of the learning analytics for the many policy makers in spaces of education and information and communication technologies in Europe. Jisc - a non-departmental public body responsible for promoting the use of information and communications technology (ICT) in higher education in the United Kingdom - published its code of practice for learning analytics for guiding higher education institutions in their implementation activities (Sclater \& Bailey, 2015). The code is a result of a very thorough process engaging a board range of stakeholders and through publication of a comprehensive literature review (Sclater, 2015). The Australian Government's Office for Learning and Teaching (OLT) also released a report (Colvin et al., 2015), which offers guidelines for the critical tasks higher education institutions need to undertake to aid learning analytics implementations. Both the Jisc and OLT reports fulfill a significant gap in the existing literature by providing practical guidelines in high demand by many institutions that are exploring the ways of how to engage in system-wide implementation of learning analytics.

\section{LOOKING AHEAD}

Since its early days, recognizing the multi-disciplinary nature of our field, SoLAR aimed to build bridges with other fields related to learning analytics. We have been fortunate enough to establish strong partnership links with educational data mining researchers and the International Educational Data Mining Society (IEDMS). George Siemens and Ryan Baker - presidents of SoLAR and IEDMS at the time wrote an important piece (Siemens \& Baker, 2012, p. 252) arguing for "increased and formal communication and collaboration between these communities in order to share research, methods, and tools for data mining and analysis in the service of developing both fields". Examples of this collaboration are well demonstrated through numerous formal and informal occasions - e.g., SoLAR 
organized LASI 2013 and LASI 2014 in assistance with IEDMS (in addition to several other partners), while numerous individuals from both communities participated in the organization of or presentation of papers at their main annual conferences (EDM and LAK) and published in their journals (Journal of Educational Data Mining and Journal of Learning Analytics). This exchange between the two communities is presently a very healthy state and many new exciting collaborations are underway. We would also like to take an opportunity to express our great appreciation for the work done in the development of these bridges to both George Siemens and Ryan Baker - whose presidency terms ended earlier this year. George and Ryan have well demonstrated visionary leadership, outstanding work ethic for their respective communities and an unconditional commitment to forging relationships among the two communities of researchers and practitioners. We would also like to take this opportunity to congratulate Mykola Pechenizkiy on his election as the President of IEDMS and look forward to working with him and other educational data mining researchers on new joint projects.

Although the link with educational data mining was quite natural from the very beginning, learning analytics has drawn on, builds on, and connects to many other fields such as the learning sciences, computer supported collaborative learning, technology enhanced learning, cyber-learning, learning at scale, and user modelling. The connections with other fields are obvious even through the examination of the proceedings of the main conferences of some of these related fields. For example, the recent 11th International Conference on Computer Supported Collaborative Learning (CSCL 2015) ${ }^{2}$ had nine papers, three posters, and one invited session with the phrase learning analytics in their title ${ }^{3}$. This is a remarkable change compared to CSCL 2013 where no paper used learning analytics in their title. This does not include quite a bit of work, potentially presented at both CSCL 2013 and CSCL 2015, which did learning analytics without labeling it as such. Initiated by Carolyn Penstein Rosé - the new President of the International Society of the Learning Sciences (ISLS) - regular meetings have been scheduled for coordination of the organizations behind some of these related fields. In addition to SoLAR, the organizations represented on these coordination meetings are ISLS, EDM, International Artificial Intelligence in Education Society (IAIEDS), European Association for Technology Enhanced Learning (EATEL), User Modeling Inc., the steering committee of the ACM Learning at Scale conference, and the Center for Innovative Research in Cyber-learning (CIRCL). This has already resulted in joint panels on grand research challenges organized at the CSCL 2015 and EDM 2015 conferences. We can expect this trend to continue and further accelerate in the future. An obvious indicator of this trend is the recently announced LAK 2016 conference - hosted by the University of Edinburgh in April 2016. The conference specifically calls for papers that look at enhancing impact through convergence of communities for grounding, implementation and validation ${ }^{4}$. In this spirt of bridge building, it is exciting to see that the LAK conference will be collocated with the third Annual ACM Conference on Learning at Scale (L@S $2016)^{5}$.

\footnotetext{
${ }^{2}$ http://www.isls.org/cscl2015/

${ }^{3}$ Many thanks to Alyssa Wise for compiling and sharing this information.

${ }^{4}$ http://lak16.solaresearch.org/?page_id=6

${ }^{5}$ http://learningatscale.acm.org/las2016/
} 
(2015). Learning Analytics - A Growing Field and Community Engagement. Journal of Learning Analytics, 2(1), 1-6.

\section{IN THIS ISSUE}

This issue features a special section that builds an important bridge between learning analytics and educational psychology by featuring the special section dedicated to self-regulated learning and learning analytics. Learning analytics brings the potential to understand and optimize learning and the environments in which learning happens by using data about learners and learning situations. For learning analytics to realise its potential, it is necessary to understand what cognitive, metacognitive, affective and motivational states influence learners' decisions when studying and when analytics are fed back to learners to reflect on their learning. We have been fortunate to have Ido Roll and Philip $\mathrm{H}$. Winne - leading experts in self-regulated learning and learning analytics - to take a lead on this topic and guest edit this special section. Roll and Winne compiled a special issue that features five exciting articles that look at different angles of the linkage between learning analytics and self-regulated learning.

This issue also features two regular research papers. Very much in sync with highly represented interests in using different methods for analysis and interpretation of discourse and text expressed in several papers presented at LAK 2015 (Baron et al., 2015), Justin Reich, Dustin Tingley, Jetson Leder-Luis, Margaret E. Roberts, and Brandon Stewart introduce the Structural Topic Model - a computational method for language analysis - and showcase its use for computationally-aided discovery and reading for student generated text in massive open online courses. In line with the topic, Simon Knight and Karen Littleton map the lay of the land of discourse-centered learning analytics (DCLA) and discus specific contributions that DCLA brings to the table in contrast to computational methods for discourse analysis.

\section{BEYOND THIS ISSUE}

The process of setting up a new journal is highly demanding and requires involvement and contributions of numerous parties and individuals. As learning analytics connects with many well-known and emerging themes related to learning and education, we felt that arranging different special sections of the journal dedicated to some specific topics is a good way to stimulate engagement of a broad group of interested authors. We have been fortunate to work with many outstanding researchers who were willing to contribute their time and expertise to lead and guest edit several special sections that will be published in the coming issues. At the moment, the special sections on the following topics are being prepared:

- Learning analytics and learning theory guest edited by Alyssa Wise and David Williamson Shaffer

- Multimodal learning analytics guest edited by Xavier Ochoa and Marcelo Worsley

- Ethics and privacy in learning analytics guest edited by Hendrik Drachsler, Rebecca Ferguson, Tore Hoel, and Maren Scheffel

- Learning analytics for $21^{\text {st }}$ century competencies guest edited by Simon Buckingham Shum and Ruth Deakin Crick

- Tutorials in learning analytics methods and techniques guest edited by Dragan Gašević and Mykola Pechenizkiy 
(2015). Learning Analytics - A Growing Field and Community Engagement. Journal of Learning Analytics, 2(1), 1-6.

- Dataset descriptions for learning analytics guest edited by Stefan Dietze, Hendrik Drachsler, George Siemens, and Davide Taibi

- Selected and revised best papers presented at LAK'15 guest edited by Paulo Blikstein, Agathe Merceron, and George Siemens

We ask you stay tuned and watch out for the publication of these exciting special sections in the future issues of the journal. In the meantime, enjoy the papers published in this issue. And, do not forget to submit your manuscripts reporting on your recent research and practice results in the near future. We would also very much like to learn about your ideas for the new special sections and other ideas that you think could make the journal an even a better place for the exchange of the state of the art results and ideas in learning analytics.

\section{REFERENCES}

Baron, J., Lynch, G., Maziarz, N., Blikstein, P., Merceron, A., \& Siemens, G. (Eds.). (2015). LAK '15: Proceedings of the Fifth International Conference on Learning Analytics And Knowledge. New York, NY, USA: ACM.

Colvin, C., Rogers, T., Wade, A., Dawson, S., Gašević, D., Buckingham Shum, S., ... Fisher, J. (2015). Student retention and learning analytics: $A$ snapshot of Australian practices and a framework for advancement (Research Report). Canberra, Australia: Office of Learning and Teaching, Australian Government.

Dawson, S., Gašević, D., Siemens, G., \& Joksimovic, S. (2014). Current State and Future Trends: A Citation Network Analysis of the Learning Analytics Field. In Proceedings of the Fourth International Conference on Learning Analytics And Knowledge (pp. 231-240). New York, NY, USA: ACM. http://doi.org/10.1145/2567574.2567585

LACE Project. (2015). Policies for Educational Data Mining and Learning Analytics Briefing. Retrieved July 14, 2015, from http://www.laceproject.eu/spring-briefing/

Mirriahi, N., Gasevic, D., Dawson, S., \& Long, P. D. (2014). Scientometrics as an Important Tool for the Growth of the Field of Learning Analytics. Journal of Learning Analytics, 1(2), 1-4.

Sclater, N. (2015). Code of practice for learning analytics: A literature review of the ethical and legal issues. Jisc. Retrieved from http://repository.jisc.ac.uk/5661/1/Learning_Analytics_A_Literature_Review.pdf

Sclater, N., \& Bailey, P. (2015). Code of practice for learning analytics. Jisc. Retrieved from https://www.jisc.ac.uk/guides/code-of-practice-for-learning-analytics

Siemens, G., \& Baker, R. S. J. d. (2012). Learning Analytics and Educational Data Mining: Towards Communication and Collaboration. In Proceedings of the 2nd International Conference on Learning Analytics and Knowledge (pp. 252-254). New York, NY, USA: ACM. http://doi.org/10.1145/2330601.2330661

Buckingham Shum, S., \& Ochoa, X. (2015). LASI 2015 International Network. Retrieved July 14, 2015, from http://solaresearch.org/events/lasi/lasi2015/ 